\title{
Self-service Technology Behavioral Intention: Indonesian Air Passengers
}

\author{
Echo Perdana Kusumah ${ }^{1, *}$ Ratih Huriyati ${ }^{2}$ Heny Hendrayati ${ }^{3}$ \\ ${ }^{1}$ Universitas Pendidikan Indonesia \\ ${ }^{2}$ Universitas Pendidikan Indonesia \\ ${ }^{3}$ Universitas Pendidikan Indonesia \\ *Corresponding author. Email: echopk@upi.edu
}

\begin{abstract}
This research aims to better understand air travelers' expectations concerning the dimensions of rapid travel options. The analysis proposed an adaptive model that incorporates the advantages of self-check-in kiosk, perceived ease of use and perceived usefulness, passenger attitude, and behavioral intentions. An online survey study was carried out in Indonesia using purposive surveys, and there are a total of 600 valid answers. All hypotheses are acknowledged and verified by empirical results. Travelers do not automatically establish optimistic expectations or prefer to take advantage of an auto check kiosk because the facility is easy to use. Their mindset and expectations are defined by their belief that self-checking advantages are useful. While experienced passengers do not see using self-checking kiosks as an obstacle, it has been found that the perceived usefulness effect has a substantial influence on passengers 'attitudes.
\end{abstract}

Keywords: self check in kiosk, intention.

\section{INTRODUCTION}

The consumers 'preference for a more convenient travel environment. Six areas of fast-preparation, including check-in \& electronic check, ready-luggage, documentation checks, booking re-booking, selfboarding, and baggage recovery, are addressed by the International Air Transport Association (IATA). In compliance with IATA (2019) [1], fast-travel facilities should create value for travelers, airlines, and airports. Airline operators can increase customer satisfaction, raise discounts and boost profits. At the end of the day, accelerated air transport services allow airports to maximize service quality, increase airport architecture and functionality, minimize costs and preserve a highsecurity standard.

Software changes the way consumers set up selfservice and how they interpret markets [2,3]. Researchers conducted quantitative studies to test client responses to multiple types of self-service technology
(SST), including airport kiosks [4-7]. Nevertheless, not much empiric research has taken a system-atic approach to analyze accelerated air travel systems at airports and related customer reactions in developing countries such as Indonesia. Therefore, we have attempted to address this study vacuum by performing an empirical review to check the relationship between check-in airport infrastructure and the self-check-in defined by IATA.

In specific, the present work aims to better understand air travelers' expectations concerning the dimensions of rapid travel options (e.g., self-checking). Therefore, we generated an integrated model using the Theory Planned Behavior (TPB) and Technology Acceptance Model (TAM) model to give a clearer understanding of what options are possible for air services and what sort of decisions Indonesian air passengers make on pursuing SST air services.

The SST systems [8] typically represent people, guidance, and self-help. SST Customer Service offers 
customer support, and SST lets businesses perform basic aviation operations without any interaction with company employees. Self-help SST offers mobile software for analysis and planning. Self-Service Technologies (SST) is a series of technical frameworks that allow clients access to online information systems or computers without trained personnel to attend their service activities [9]. This architecture leads to fair market participation. Because SST is becoming more and more critical to the airport industry, researchers have carried out detailed investigations on the use of SST from passengers' points of view. Reference [10] was researched SST use on an airport in Taiwan. The findings indicate that direct coordination between SST and passengers in service processes may increase passengers' intention to use check-in kiosks. The usage of the check-in desks at the Singapore Changi Airport has been recorded by [5]. The relationship between airport technologies of different types and the trust, enjoyment, and satisfaction of travelers was explored [11].

Introducing the explanations why customers embrace or oppose computer programs. Reference [12] initially established the Technology Acceptance Model (TAM). The simple TAM consists of three key elements: perceived value, perceived ease of use, and actual usage [12]. TAM also offers a check-in kiosk [10] to analyze the customer acceptance of airport SSTs. TAM states that two main variables defining customer acceptances of information technology are perceived usefulness and perceived ease of use [12]. Not all the study has a substantial positive correlation with the study which shows no link or even a reversing association but compare with the summaries of research findings $[13,14]$. Therefore, in the sense of air travel, it is also vital to discuss TAM.

Earlier work has shown that the two variables have significant consequences for behavioral actions (example: [15,16] and attitude (example: $[17,15]$. Many researchers have explored the in-terrelationship of these two determinants. Furthermore, rationality implies that the more self-check-in experienced by travelers are advantageous, the more self-check-in services should be expected. Thus, airlines and policy-makers will devise efficient forms of supplying passengers with easy transportation services with a more profound knowledge of customer attitudes. So, we assume:

H1: Advantages of self-check-in kiosk positively affect perceived ease of use.

$\mathrm{H} 2$ : Advantages of self-check-in kiosk positively affect perceived usefulness.

The research was undertaken based on many wellknown behavioral hypotheses in order to evaluate passengers ' motives in air transport through fast air travel services; specifically the theory of reasoned action [18], the theory of planned behavior [19], and the concept of technology acceptation. The theory of reasoned action stipulates that a person's purpose of perform-ing a particular job, affected by attitudes and social expectations, defines their actual acts. Since not all actions are influenced by volitional control [19], the proposed behavioral framework introduces an external mechanism of assumed behavioral regulation to cope with the issue. In a standard TPB model, the intention is a significant parameter ele-ment.

Previous research by reference [20] also reveals that marketing experts ensure air travelers 'expected advantages are matched with their specifications. The degree of affection of air travelers may be used to forecast the product's reception, including the likelihood of purchasing or buying the product. The analysis also includes behavioral intention as a significant endogenous variation for air travel services in tourism, hospitality, and travel research [21-23]. While air passengers ' behavior intention and attitudes to air travel services (self-check-in ki-osk) differ with the strength and affections for mo-bile technology, previous study [20] have shown that the beneficial effect of mobile tech-nology on the user can be changed and that, in turn, the positive attitude towards air travel services is established for the air passenger. So, we assume.

H3: Perceived ease of use positively affects the passengers' attitude.

H4: Perceived usefulness positively affects the passengers' attitude.

H5: Passengers' attitude positively affects behavioral intentions

\section{METHODS}

\subsection{Sample and Data Collection}

The present research adopted the purposeful sampling method, based on recommendations made by [24] to classify qualified respondents and thus optimize sample representation. The questionnaire aimed at respondents who used self-check-in kiosks at the airport as a self-service technology tool. Respondents in this study are Indonesian air passengers. The study included respondents who met the above requirements. To ensure appropriate respondents, the screening question is asked ("Have you used self-check-in at an airport or not?"). This study collected data from October to November 2019 using social media platforms such as WhatsApp. Online surveys were often assumed to be effective because respondents could access individuals in rural, regional regions and effectively enter specific audiences that are technically competent [25].

A total of 600 participants returned the questionnaires. In addition to successful parameter 
estimation, a minimum of 200 respondents is needed for the structural equation model (SEM), as reference [26] suggested. The above findings thus showed that we had an adequate sample size. The survey's demographic characteristics, females $(53.83 \%)$, male $(46.17 \%), 60.5 \%$ of the total respondents were $31-40$ years of age, and $84.67 \%$ were married. Besides, $93.83 \%$ of respondents received a bachelor's degree or more.

\subsection{Instrument Development}

A survey consisted of questions on self-check-in kiosk advantages, perceived ease of use, perceived usefulness, passenger attitude, behavioral intention, and respondent demographic profile. A draft of the survey instrument was distributed in electronic format to 30 colleagues and other pilot testing contacts. The questionnaire was marginally updated to improve its transparency and reading distance based on the findings and the positive input. The pilot study also showed that the survey was done in about 10 minutes. Reference [1] Fast Air Travel Program concept has delivered three items for measuring self-check kiosk advantages. Participants were questioned to show that they had benefitted from a col-lection of self-service technology. A five point Likert scale of 1 (strongly disagree) to 5 (strongly agree) has been used. Research by [1] (perceived ease of use, perceived usefulness) and [19] (passenger attitudes, behavioral intentions) were designed and modified to quantify the five variables in the conceptual model. The questionnaire was translated into Indonesian, while the initial pieces in the literature are in English.

\subsection{Data Analysis}

Several of refrence [27] protocols led the method in this phase. Such measures involved the design of experiments in analyzing subjects in specific communities, the conduct of Confirmatory Factor Analysis (CFA) to validate the structure of a theoretical component, and the evaluation of building validity and internal coherence within the study to ensure scale performance. CFA was used as a multivariate strategy to check if the correlations between manifest and latent variables are pre-specified and to assess if our defined factors correlate to the truth (actual data). This offers a check of consistency with our measurement theory and measures how well latent mechanisms are described by calculated variables, which helps one to either affirm our theory or deny it [28]. The CFA test has found intense factor loads over 0.65 , and scholars have often acknowledged loads over 0.60 [29]. The considerably strong loading of the items is evidence of convergent validity, the average variance extracted (AVE) 0.5 and above, reliability construct (CR) should $0.6-0.7$ or higher [30], and discriminant validity (Chi-square differences) [31]..

\section{RESULT AND DISCUSSION}

\subsection{Confirmatory factor analysis (CFA)}

A two-stage model of structural equation (SEM) [31] was used to check the research model. CFA was initially performed to determine model fit ability, reliability, and validity, accompanied by studying the conceptual paths used to test hypotheses for research. The sample size $(\mathrm{N}$ $=600)$ is deemed large enough to balance the possible misspecification factor and configuration complexity [26]. This shows that the multinormal statement is substantiated. Instead, after analyzing reliability and relevance, we measured the consistency and appropriateness of our model. The findings reveal that most of the loading factor was higher than 0.67 , while one item (perceived usefulness) was omitted to achieve higher AVE. For the context of composite reliability, there was evidence that all composite reliability values reached 0.6 and higher. In addition, all AVE values surpass 0.50 and reflect convergent validity

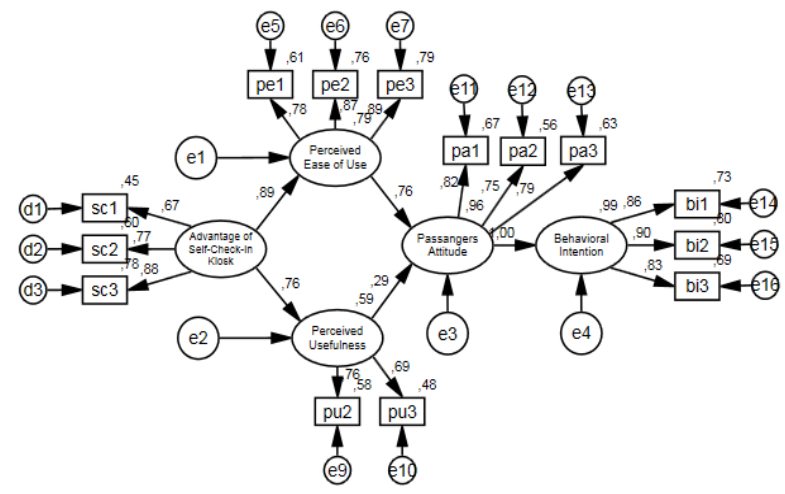

Figure 1. Structural equation model

\subsection{Hypotheses Tesing}

The findings found that the advantages of the selfcheck-in kiosk can be explained by all the factors examined in this study. The advantages of self-check-in kiosk positively influence perceived ease of use $(\beta=$ $0.886, \mathrm{p}<0.01)$, and perceived usefulness $(\beta=0.765, \mathrm{p}$ $<0.01$ ), supporting H1 and H2. Per-ceived ease of use positively influences passengers attitude $(\beta=0.765, \mathrm{p}<$ 0.01) supporting H3. Per-ceived usefulness positively influences passengers attitude $(\beta=0.285, \mathrm{p}<0.01)$ supporting H4. Moreover, passengers attitude positively influences behav-ioral intention $(\beta=0.996, p<0.01)$ supporting H5. Thus, all of the hypotheses are supported.

\subsection{Discussion}

The results indicate that travelers do not automatically establish optimistic expectations or prefer to take advantage of an auto check kiosk because the facility is easy to use. Their mindset and expectations are 
defined by their belief that self-checking advantages are useful. While experienced passengers in our sample do not see using self-checking kiosks as an obstacle, it has been found that the perceived usefulness effect has a substantial influence on passengers 'attitudes. Faster and simplified operation tends to refer only to passengers' flight categories that hold no more than 7 kilograms of luggage, while some respondents do hold luggage exceeding cabins 'baggage capacity. This is achieved by passengers of airlines as they need souvenirs for their friends or neighbors. It has become one of the dominant Indonesian characteristics of both low- and higheducation. Therefore, the value of the perceived usefulness aspect must not be overlooked by advertisers designing self-checking kiosk services. In previous research, related findings were published. For instance, [32] concluded that customer preparedness for technology increases perceived usefulness, ease of use, efficiency, and intention. The findings demonstrate consumer electronics' willingness to attenuate the favorable relationship between perceived ease of use and SST attitude. Reference [33] have shown that the perceived usefulness and easy-to-use approach to using a self-service kiosk by travelers are greatly affected.

A few experiments explored the context for airline selection [34], perceptions and expectations for air travel [35], and online ticket selling strategy [36], behavior to buy online tickets [38].

\section{CONCLUSION}

However, the self-check-in kiosk's implementation inside an optimized TPB and TAM system was not researched for the author in the best information. Depending on this report, air-lines and airports administrators provide a variety of important take aways. The lowest of three subdimensional structures were air travelers' expectations of the benefits of delayed/canceled self-checking items. Managers may choose to base their primary attention on delayed/canceled item devel-opment and marketing. Therefore, because of the understanding of the value of self- kiosks, air travelers' behaviors and intention, the perceived ease of use, and the perceived usefulness, managers should be attentive to motivating travelers to take advantage of the SST offering. When the perceived usefulness and ease of use affected the mindset, this would contribute to self-kiosk services expectations.

\section{REFERENCES}

[1] Fast Travel Program, IATA, 2020. [Online]. Avaible:

https://www.iata.org/en/programs/passenger/fasttravel/

[2] T. Hilton, T. Hughes, E. Little, and E. Marandi, "Adopting self-service technology to do more with less,” J. Serv. Mark., 2013.
[3] P. Kelly, and J. Lawlor, "Adding or destroying value? user experiences of tourism self-service technologies,” J. Hosp. Tour. Insights., 2019.

[4] M. Blut, C. Wang, and K. Schoefer, "Factors influencing the acceptance of self-service technologies: A meta-analysis," J. Serv. Res., vol. 19, pp. 396-416, 2016.

[5] C.Ng.Y.Lv.Y. Lee, and P. Taezoon, "Empirical analysis of a self-service check-in implementation in Singapore Changi Airport," Int. J. Eng. Bus. Manag, vol. 6, pp. 6-6, 2014.

[6] P. Regan, "Flying on course: public-sector innovation at Shannon airport," Int. J. Entrep. Innov., vol. 18, pp. 128-135, 2017.

[7] Y.So.KKF. Wang, and BA. Sparks, "What technology-enabled services do air travelers value? Investigating the role of technology readiness," J. Hosp. Tour. Res., vol. 41, pp. 771-796, 2017.

[8] M.L. Meuter, A.L. Ostrom, R.I Roundtree, and M.J. Bitner, "Self-service technologies: understanding customer satisfaction with technology-based service encounters," J. Mark., vol. 64, pp. 50-64, 2000.

[9] A. Scherer, N.V. Wünderlich, and F.V. Wangenheim, "The value of self-service: long-term effects of technology-based self-service usage on customer retention," MIS Q., vol. 39, pp. 177-200, 2015.

[10] E.C. $\mathrm{Ku}$, and C.D. Chen, "Fitting facilities to selfservice technology usage: evidence from kiosks in Taiwan airport," J. Air Transp. Manag., vol. 32, pp. 87-94, 2013.

[11] V. Bogicevic, M. Bujisic, A. Bilgihan, W. Yang, and C. Cobanoglu, "The impact of traveler-focused airport technology on traveler sat-isfaction," Technol. Forecast. Soc. Change,. Vol. 123, pp. 351-361. 2017.

[12]F.D. Davis, "Perceived usefulness, perceived ease of use, and user acceptance of infor-mation technology," MIS Q., pp. 319-340, 1989.

[13]A.K. Kaushik, and Z. Rahman, "An alternative model of self-service retail technology adoption," J. Serv. Mark., 2015.

[14] P. Legris, J. Ingham, and P. Collerette, "Why do people use information technology? A critical review of the technology acceptance model," Inf. Manage,. Vol. 40, pp. 191-204, 2003.

[15]E.P. Kusumah, "Utilization of Online Application among International Students for Entry into Universiti Utara Malaysia (UUM)," Ph.D. dissertation). Universiti Utara Malaysia, Kuala Lumpur, 2009.

[16] J. Yu, I.. Ha, M. Choi, and J. Rho, "Extending the TAM for a t-commerce," Inf. Manage., vol. 42, pp. 965-976, 2005.

[17] J.H. Choi, and J.W. Park, "A study on factors influencing CyberAirport usage intention: An 
Incheon International Airport case study," J. Air Transp. Manag., vol. 42, pp. 21-26, 2015.

[18] M. Fishbein, and I. Ajzen, "Understanding attitudes and predicting social behavior," 1980.

[19]I. Ajzen, "The theory of planned behavior," Organ. Behav. Hum. Decis. Process., vol. 50, pp. 179$211,1991$.

[20]H.W. Akram, M. Anwar, and M.A. Khan, "CoBranding: A case study of Air India and SBI card," Bus. Dimens., vol 1, pp. 49-57, 2014.

[21] M.D. Alvarez, and S. Campo, "The influence of political conflicts on country image and intention to visit: A study of Israel's image" Tour. Manag,. vol. 40, pp. 70-78, 2014.

[22] J.K. Ayeh, N. Au, and R. Law, "Predicting the intention to use consumer-generated media for travel planning," Tour. Manag., vol. 35, pp. 132143, 2013.

[23] J.S. Horng, C.H. Liu, H.Y. Chou, and C.Y. Tsai, "Understanding the impact of culinary brand equity and destination familiarity on travel intentions," Tour. Manag., vol. 33, pp. 815-824, 2012.

[24]E. Fossey, C. Harvey, F. McDermott, and L. Davidson, "Understanding and evaluating qualitative research,” Aust. N. Z. J. Psychiatry., vol. 36, pp. 717-732, 2002.

[25] K.B. Wright, "Researching Internet-based populations: Advantages and disadvantages of online survey research, online questionnaire authoring software packages, and web survey services," J. Comput.Mediat. Commun," vol. 10, JCMC1034, 2005.

[26] J. Hair, R. Anderson, B. Babin, and W. Black, "Multivariate data analysis: A global perspective, $7^{\text {th }}$ ed. Pearson Upper Saddle River. NJ. 2010.

[27] R.G. Netemeyer, W.O Bearden, and S. Sharma, "Scaling procedures: Issues and applications, Sage Publications. 2003.
[28] M. Demirbag, E. Tatoglu, M. Tekinkus, and S. Zaim, "An analysis of the relationship between TQM implementation and organizational performance: evidence from Turkish SMEs," J. Manuf. Technol. Manag., vol. 17, pp. 829-847, 2006.

[29] J.F. Hair Jr, M. Sarstedt, L. Hopkins, and V.G. Kuppelwieser, "Partial least squares structural equation modeling (PLS-SEM)," Eur. Bus. Rev., 2014.

[30] J.F. Hair Jr, M. Sarstedt, C.M. Ringle, and S.P. Gudergan, "Advanced issues in partial least squares structural equation modeling. Sage Publications. 2017.

[31] J.C. Anderson, and D.W. Gerbing, Structural equation modeling in practice: $\mathrm{A}$ review and recommended two-step approach. Psychol. Bull. 103, 411, 1988.

[32] R.P. Fisk, L. Patricio, J.S.C. Lin, and H.C. Chang, "The role of technology readiness in self-service technology acceptance,” Manag. Serv. Qual. Int. J., 2011.

[33] M. Kim, and H. Qu, "Travelers' behavioral intention toward hotel self-service kiosks usage," Int. J. Contemp. Hosp. Manag., 2014.

[34] T. Buaphiban, "Determination of factors that influence passengers airline selection: A study of low cost carriers in Thailand," 2015.

[35] L. Davison, C. Littleford, and T. Ryley, “Air travel attitudes and behaviours: The development of environment-based segments," J. Air Transp. Manag., vol. 36, pp. 13-22, 2014.

[36] Y. Vakilalroaia, and A.H Fatorehchi, "Technology Acceptance Model and Theory of Planned Behavior Functions in Electronic Ticket Sales Strategy of Iranian Airlines (Case study; Kish Airline)," 10.

[37]E. Bigné, S. Sanz, C. Ruiz, and J. Aldás, "Why some internet users don't buy air tickets online, in: Information and Communication Technologies in Tourism 2010," Springer., pp. 209-221, 2010 